\title{
MK2206 enhances the cytocidal effects of bufalin in multiple myeloma by inhibiting the AKT/mTOR pathway
}

\author{
Ru-Fang Xiang ${ }^{1,4}$, Yan Wang ${ }^{1,4}$, Nan Zhang ${ }^{1}$, Wen-Bin $\mathrm{Xu}^{1}$, Yang Cao ${ }^{2}$, Jia Tong ${ }^{1}$, Jun-min Li, ${ }^{*, 1}$, Ying-Li Wu ${ }^{*, 3}$ and Hua Yan ${ }^{*, 1}$
}

Despite the development of promising cancer therapeutic drugs, multiple myeloma (MM) remains an incurable disease. Bufalin is a bufanolide steroid compound of the traditional Chinese medicine Chan Su that was previously shown to exert growth suppression effects on myeloma cell lines. Previous studies conducted by our group demonstrated that bufalin activated the AKT/mTOR pathway in myeloma cells, which is considered an essential pathway to disease progression and is related to drug resistance in MM. In view of the significant role of AKT in MM, the allosteric AKT inhibitor MK2206 was selected in order to enhance the antitumor effects of bufalin in different MM cell lines (NCl-H929, U266, LP-1 and RPMI8226). The data indicated that MK2206 enhanced the cytotoxicity of bufalin in MM cells, via the suppression of cellular proliferation and the induction of apoptosis, as demonstrated by cleavage of apoptosis-related proteins. This effect was further noted in the presence of exogenous interleukin- 6 and/or following the co-culture of MM cells with bone marrow stromal cells (BMSC). This process was associated with the inhibition of the AKT/ mTOR pathway. The combination of bufalin with MK2206 reduced the secretion of IL-6 in U266 cells. The combined treatment exhibited similar anti-MM effects in bortezomib-resistant cell lines (NCl-H929R, U266R). In addition to the in vitro cell line models, the synergistic effect was noted in primary MM cells and in MM xenografts of BALB-C and NOD-SCID mice. In conclusion, the data suggested that MK2206 significantly enhanced the cytocidal effects of bufalin in MM cells, regardless of the sensitivity to bortezomib, via the inhibition of the AKT/mTOR pathway. The study provided the basis of a promising treatment approach for MM. Cell Death and Disease (2017) 8, e2776; doi:10.1038/cddis.2017.188; published online 11 May 2017

Multiple myeloma is a heterogeneous hematological malignancy. It is estimated that 30330 new cases and 12650 associated deaths have been reported in the United States in 2016 due to $\mathrm{MM}$. $^{1}$ The use of new drugs namely, proteasome inhibitors (PIs), immunomodulatory drugs (IMiDs) and cell signaling protein inhibitors has contributed significant improvements in $\mathrm{MM}^{2}$ Despite the promising advances in the development of MM therapy, MM remains incurable. Thus, more potent and selective drugs that target MM tumor cells are required in order to overcome drug resistance and improve patient outcome.

The AKT family of kinase enzymes is a key signaling partner of the PI3K pathway and consists of AKT1, AKT2 and AKT3. The latter enzymes play a pivotal role in cell survival and growth, and are frequently deregulated in a majority of human cancers. ${ }^{3}$ Previous studies have shown that the AKT kinase is activated in MM plasma cells, which sensitizes the antiapoptotic pathway, mediates MM pathogenesis and accelerates disease progression. ${ }^{4}$ Furthermore, the activation of AKT is involved in osteoclast formation that can in turn cause osteolysis. ${ }^{5}$ On the basis of these studies, AKT targeting is considered a rational strategy for MM treatment. ${ }^{6}$ MK2206 is a potent, oral allosteric AKT inhibitor that enhances the antitumor efficacy of chemotherapeutic agents. ${ }^{7-9}$ MK2206 is well tolerated and exerts optimal safety profile, as demonstrated in the first-in-human clinical trial. ${ }^{10}$

Bufalin, an active ingredient of the traditional Chinese medicine Chan $\mathrm{Su},{ }^{11,12}$ has been reported to have antitumor effect on various types of cancers, including leukemia, ${ }^{13-16}$ breast, ${ }^{17}$ lung, liver, and pancreatic cancers. ${ }^{18}$ The previous study conducted by our group demonstrated that bufalin induced cellular apoptosis in MM cells, ${ }^{19}$ whereas a more recent study indicated that bufalin induced phosphorylation of AKT (p-AKT) in MM cell lines, which may counteract the cytotoxic effect of this compound and cause drug resistance, partially due to hyperphosphorylation of $\mathrm{AKT}^{20}$

In the present study, the synergistic effects that were induced by the combination of bufalin and MK2206 were investigated in various myeloma cell lines (H929, U266, LP-1 and RPMI8226). A total of two out of four cell lines namely, H929R and U266R are bortezomib resistant. Furthermore, the combination treatment moderately enhanced the cytotoxicity and augmented apoptosis in myeloma cells via suppression of the AKT/mTOR pathway and the downregulation of $\mathrm{Bcl}-2$ and

\footnotetext{
${ }^{1}$ Department of Hematology, Rui-Jin Hospital, Shanghai Jiao-Tong University School of Medicine, Shanghai 200025, China; ${ }^{2}$ Department of Hematology, The Third Affiliated Hospital of Suzhou University, The First People's Hospital of Changzhou, Changzhou 213003, Jiangsu Province, China and ${ }^{3}$ Hongqiao International Institute of Medicine, Shanghai Tongren Hospital/Faculty of Basic Medicine, Chemical Biology Division of Shanghai Universities E-Institutes, Key Laboratory of Cell Differentiation and Apoptosis of the Chinese Ministry of Education, Shanghai Jiao Tong University School of Medicine, Shanghai 200025, China

${ }^{*}$ Corresponding author: H Yan or J-M Li, Department of Hematology, Rui-Jin Hospital, Shanghai Jiao-Tong University School of Medicine, Shanghai 200025, China. Tel: +86 2164370045 671901; Fax: +86 0216466 4325; E-mail: yanhua_candy@ 163.com or drlijunmin@ 126.com

or Y-L Wu, Hongqiao International Institute of Medicine, Shanghai Tongren Hospital/Faculty of Basic Medicine, Chemical Biology Division of Shanghai Universities E-Institutes, Key Laboratory of Cell Differentiation and Apoptosis of National Ministry of Education, Shanghai Jiao Tong University School of Medicine, Shanghai 200025, China. Tel: +86 2163846590 776916; Fax: +86 216415 4900; E-mail: wuyingli@ shsmu.edu.cn

${ }^{4}$ These authors contributed equally to this work.

Received 09.10.16; revised 10.3.17; accepted 21.3.17; Edited by M Diederich
} 
a

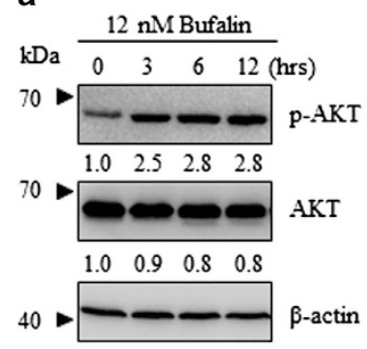

H929

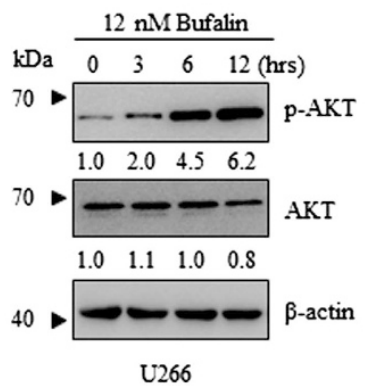

H929 b

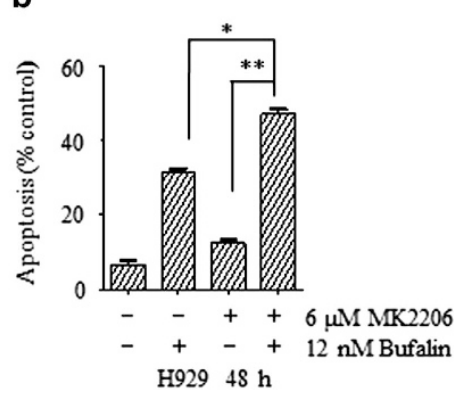

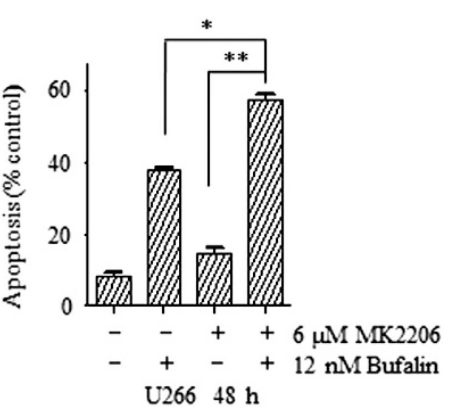

U266
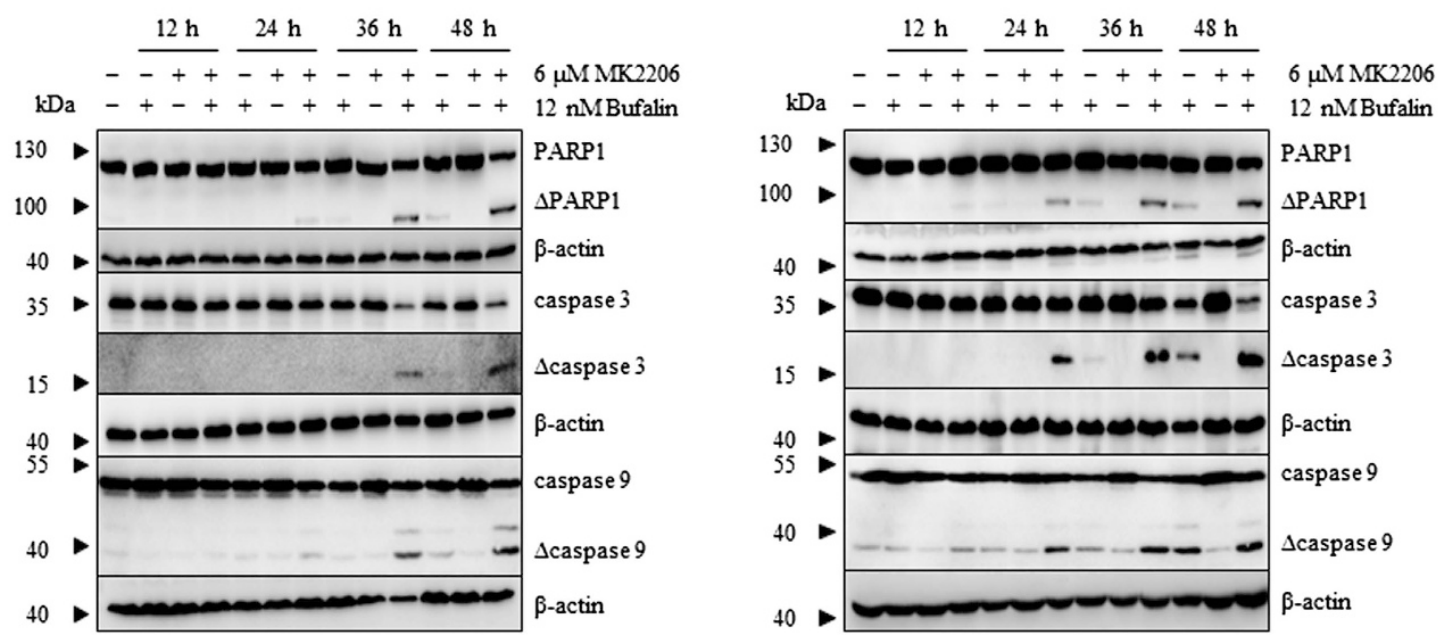

Figure 1 Bufalin-activated AKT in MM cells and the combination of bufalin with MK2206 increased the rate of apoptosis induction. (a) H929 and U266 cells were incubated with $12 \mathrm{nM}$ of bufalin for $3,6,12 \mathrm{~h}$ and subsequently subjected to western blot analysis using anti-p-AKT, anti-AKT and anti- $\beta$-actin antibodies. $\beta$-actin was used as a loading control. (b) H929 and U266 cells were treated with $12 \mathrm{nM}$ of bufalin and/or $6 \mu \mathrm{M}$ of MK2206 for $48 \mathrm{~h}$ and the apoptotic rates were analyzed by flow cytometry. The apoptotic effect of the combination group was statistically different compared with treatment of bufalin and/or MK2206 alone. Each bar represented the mean \pm S.E. of triplicate experiments. The values under the bands represented the mean quantitation ratios compared with the control groups. (c) H929 and U266 cells were treated with $12 \mathrm{nM}$ of bufalin in the absence and/or presence of $6 \mu \mathrm{M}$ of MK2206 for 12, 24, 36, $48 \mathrm{~h}$ and the protein lysates were subjected to immunoblot analysis using antibodies specific against PARP, caspase-3, caspase-9 and/or $\beta$-actin. $\beta$-actin was used as a loading control. Experiments were performed in triplicate $\left({ }^{\star} P<0.05 ;{ }^{* *} P<0.01\right)$

Mcl-1 proteins. The aforementioned effects were further noted in the presence of exogenous interleukin- 6 and/or in co-culture with bone marrow stromal cells. In addition, a synergistic effect of bufalin and MK2206 was observed in primary MM cells that was proportional to that noted in a xenograft mouse model. Thus, co-treatment of bufalin and MK2206 may be a promising strategy for the treatment of MM.

\section{Results}

MK2206 potentiated growth inhibition induced by bufalin in myeloma cells. H929 and U266 myeloma cells were treated with $12 \mathrm{nM}$ of bufalin for $48 \mathrm{~h}$. The results indicated that bufalin alone moderately induced apoptosis in H929 and U266 cells (data not shown). The induction of apoptosis was accompanied with increased p-AKT levels and notably in U266 cells (Figure 1a). AKT plays a pivotal role in the development of myeloma due to the stimulation of cellular proliferation, the inhibition of apoptosis and the increase in myeloma cell motility. ${ }^{21}$ MK2206 is a potent allosteric AKT inhibitor that is currently evaluated in phase II trials for the treatment of solid tumors. Therefore, the effect of the combination of bufalin and MK2206 on cell viability was investigated in various types of MM cells, namely H929, U266, RPMI8226 and LP-1 cells. MK2206 potentiated the growth inhibition induced by bufalin in myeloma cells $(P<0.05$, Supplementary Figure S1A-D). CompuSyn synergism/antagonism analysis confirmed the synergistic effect of bufalin with MK2206 according to the $\mathrm{Cl}$ value that was below 1.0 (Table 1). The results suggested that MK2206 enhanced the effect of bufalin in myeloma cells.

The combined treatment of bufalin and MK2206 increased the induction of apoptosis via suppression of the AKT/mTOR pathway. The combination treatment of the two compounds on the induction of apoptosis was investigated in myeloma cells. H929 and U266 cells were exposed to $12 \mathrm{nM}$ of bufalin alone and/or in combination with $6 \mu \mathrm{M}$ of MK2206 for $48 \mathrm{~h}$ (Figure 1b). The number of Annexin-V/PI cells increased in the combination treatment in $\mathrm{H} 929$ and U226 cells, respectively $(P<0.05)$. The combination treatment resulted in increased levels of PARP cleavage and increased expression of cleaved caspases $-3,-8$ and -9 (Figure 1c and Supplementary Figure S2A) compared with 
Table $1 \mathrm{Cl}$ values of bufalin and MK2206 in MM cells

\begin{tabular}{lccc}
\hline Cell line & Bufalin $(\mathrm{nM})$ & MK2206 $(\mu \mathrm{M})$ & Combination index \\
\hline NCI-H929 & 1.5 & 0.75 & $0.63151 \pm 0.17898$ \\
& 3 & 1.5 & $0.35813 \pm 0.16165$ \\
& 6 & 3 & $0.62726 \pm 0.15774$ \\
& 12 & 6 & $0.39784 \pm 0.14055$ \\
U266 & 24 & 12 & $0.68673 \pm 0.11926$ \\
& 1.5 & 0.75 & $0.74681 \pm 0.12682$ \\
& 3 & 1.5 & $0.78902 \pm 0.05403$ \\
& 6 & 3 & $0.63393 \pm 0.06415$ \\
RPMI8226 & 12 & 6 & $0.48425 \pm 0.05617$ \\
& 24 & 12 & $0.54466 \pm 0.13783$ \\
& 1.5 & 0.75 & $0.98908 \pm 0.23793$ \\
& 3 & 1.5 & $0.54602 \pm 0.09387$ \\
LP-1 & 6 & 3 & $0.61654 \pm 0.11481$ \\
& 12 & 6 & $0.69458 \pm 0.03525$ \\
& 24 & 12 & $0.26182 \pm 0.08178$ \\
& 1.5 & 0.75 & $0.97739 \pm 0.25743$ \\
& 3 & 1.5 & $0.57839 \pm 0.12488$ \\
H929R & 6 & 3 & $0.57851 \pm 0.08621$ \\
& 12 & 6 & $0.60430 \pm 0.05833$ \\
& 24 & 12 & $0.54849 \pm 0.20227$ \\
U266R & 6 & 3 & $0.20565 \pm 0.08265$ \\
& 12 & 6 & $0.28958 \pm 0.06326$ \\
& 24 & 12 & $0.46241 \pm 0.20279$ \\
& 6 & 3 & $0.20333 \pm 0.09171$ \\
& 12 & 6 & $0.33709 \pm 0.09838$ \\
& 24 & 12 & $0.59512 \pm 0.23565$ \\
\hline
\end{tabular}

the single treatment. A concomitant reduction in the expression of Bid was noted (Supplementary Figure S2A), although the levels of $\mathrm{t}$-Bid (truncated Bid) were not investigated.

In order to examine whether MK2206 increased the effect of bufalin via the inhibition of p-AKT, the expression of AKT was silenced in $\mathrm{NCl}-\mathrm{H} 929$ cells using a sh-RNA sequence for AKT (shAKT-NCl-H929, Figure 2a). A decrease in cellular viability and cell cycle arrest with a concomitant induction of apoptosis were demonstrated in the presence of bufalin in shAKT-H929 cells compared with NC-H929 cells (Figure $2 b$ ). The combined effect of MK2206 and bufalin was consistent with the knockout of AKT in the presence of bufalin, indicating that the underlying mechanism may be associated with AKT inhibition. Furthermore, H929 and U266 cells were treated with $12 \mathrm{nM}$ of bufalin alone and/or in combination with $6 \mu \mathrm{M}$ of MK2206. The data indicated that bufalin treatment alone increased the levels of $\mathrm{p}-\mathrm{AKT}$ and its downstream signaling members namely, p-mTOR, p-P70S6K and p-4EBP1, whereas following addition of MK2206 the inhibition of the AKT/mTOR pathway was evident (Figure 2c). The data suggested that the addition of MK2206 enhanced the pro-apoptotic effect of bufalin via AKT inhibition.

The induction of apoptosis by combined treatment of bufalin and MK2206 was partially related to the mitochondrial pathway. Previous studies have shown that cell death induced by inhibition of AKT is associated with the increase in the expression of the apoptotic proteins namely, $\mathrm{Bcl}-2$ and $\mathrm{Mcl}-1 . \mathrm{Bcl}-2$ and $\mathrm{Mcl}-1$ belong to the anti-apoptotic members of the $\mathrm{Bcl}-2$ family ${ }^{22}$ and are important regulators in the apoptotic pathway. The expression of $\mathrm{Bcl}-2$ and $\mathrm{Mcl}-1$ was significantly abolished following $48 \mathrm{~h}$ of combined treatment of bufalin and MK2206, notably in H929 cells
(Supplementary Figure S3A). Consistent with this finding is the observation that the combination treatment resulted in a significant decrease of the mitochondrial potential (Supplementary Figure S3B).

MK2206 enhanced apoptosis induction by bufalin in primary myeloma cells. Mononuclear cells were isolated from bone marrow aspiration of 8 cases that presented with diagnosed MM (patient 1, 2, 5, 6, 7: IgG- $\lambda$ subtype; patient 3: non-secretory myeloma; patient $4: \lg A-\lambda$ subtype; patient 8 : IgG- $\kappa$ subtype). CD138 ${ }^{+}$myeloma cells were incubated with $12 \mathrm{nM}$ of bufalin alone and/or in combination with $6 \mu \mathrm{M}$ of MK2206, and the induction of apoptosis was quantified. The data indicated that bufalin and MK2206 demonstrated a moderate ability to induce apoptosis, while the combination of bufalin and MK2206 demonstrated a substantial improvement in the induction of apoptosis in seven patients (except patient $4, P<0.05$, Figure 3a). Bufalin alone or in combination with MK2206 exhibited no influence on cell viability in PBMCs obtained from healthy volunteers (Figure $3 b$ ).

Bufalin and MK2206 abrogated the IL-6-mediated cell growth in myeloma cells and effectively reduced IL-6 secretion in U266 cells. IL-6 is a cytokine that is considered a significant survival factor in $\mathrm{MM}^{23}$ as demonstrated by in vitro and in vivo studies. ${ }^{24}$ The present study aimed to examine whether the drug combination could abrogate IL-6-mediated cell growth in myeloma. The growth of H929 cells was significantly inhibited following combination treatment of bufalin and MK2206 (Figure 4a). This effect occurred regardless of the presence of IL-6 $(P<0.05)$ and was accompanied with an inhibition of p-AKT. In addition, a similar effect was observed in U266 cells (Figure 4b). The levels of IL-6 were tested under different treatment conditions, since U266 cells were shown to secrete this cytokine. ${ }^{25}$ Co-treatment of bufalin and MK2206 efficiently decreased IL-6 secretion, as demonstrated by ELISA (Figure 4c, $P<0.01$ ).

Synergistic apoptotic effect was induced by bufalin and MK2206 during co-culture of MM cells and BMSCs. Previous studies have shown that cell-cell contact between MM cells and BMSCs plays a critical role in the survival and growth of myeloma cells. Adhesion of tumor cells to BMSCs activates a multitude of signaling pathways, leading to upregulation of cell cycle regulating and anti-apoptotic proteins. $^{26}$ BMSCs were isolated from myeloma patients, and incubated in the presence of bufalin and MK2206 alone and/or in combination, in H929 and/or U266 cells, respectively. Bufalin and MK2206 moderately induced apoptosis of U266 and/or H929 cells in the presence of BMSCs. This effect was accompanied with a decrease of $\mathrm{p}-\mathrm{AKT}$ and was independent of the contact of MM cells with BMSCs (Figure $4 d-f)$. The results suggested that the combination of bufalin and MK2206 targeted MM cells directly and surpassed a cytoprotective effect that was mediated by the MM-host-BM microenvironment.

The combination of bufalin with MK2206 overcame bortezomib resistance in bortezomib-resistant cells. In the present study, H929R and U266R cells were used in 


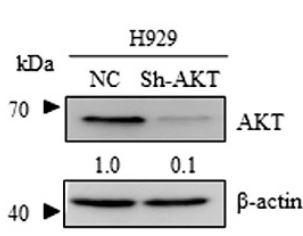

b

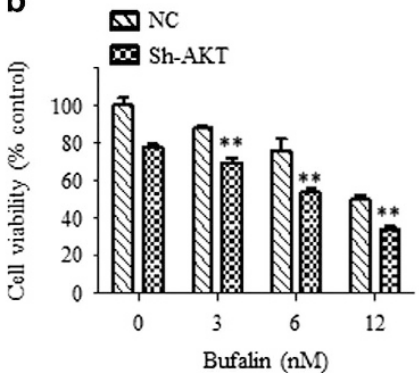

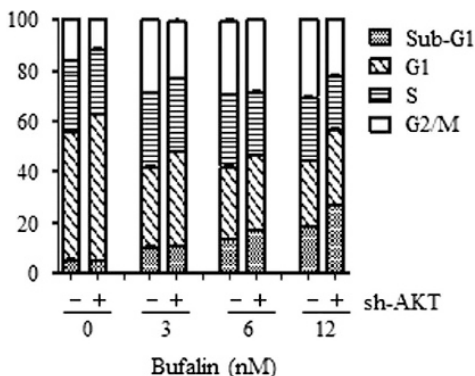

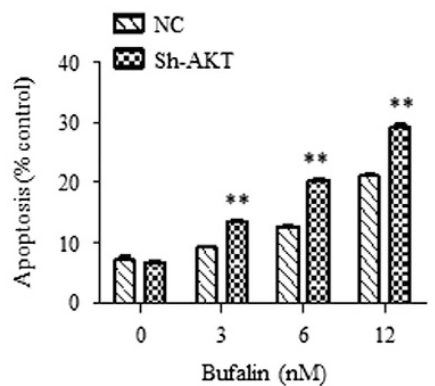

C

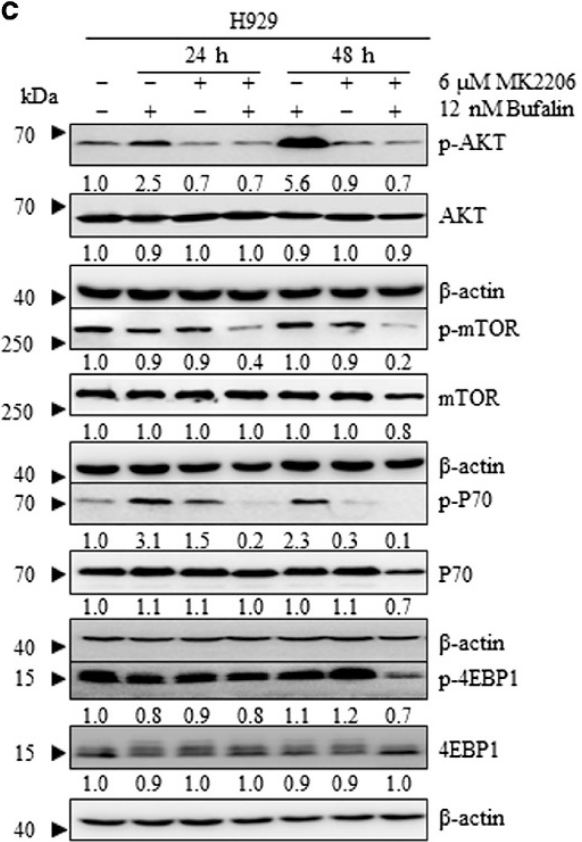

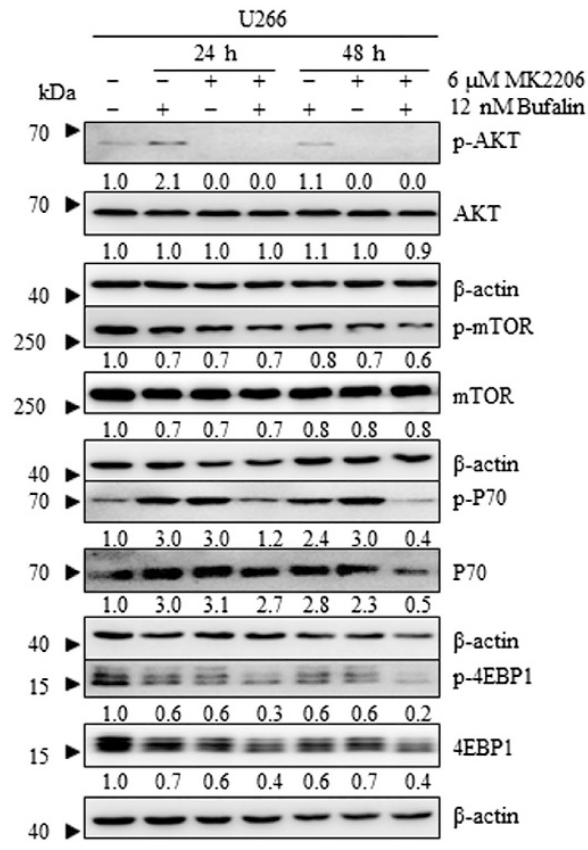

Figure 2 Induction of apoptosis following combination treatment of bufalin with MK2206 was associated with the inhibition of the AKT/mTOR pathway. (a) H929 cells were transfected with an AKT shRNA (H929 Sh-AKT) and/or a non-targeting shRNA (H929-NC) and protein lysates were subjected to Western blot analysis using antibodies specific against p-AKT and $\beta$-actin. (b) H929-NC and H929 Sh-AKT cells were incubated with 0, 3, 6, $12 \mathrm{nM}$ of bufalin for $48 \mathrm{~h}$. Cell viability was measured by CCK8 assay, whereas the cell cycle distribution was determined by flow cytometry analysis of the DNA content and cell apoptosis by the AnnexinV/PI assay. Each bar represented the mean \pm S.E. of triplicate experiments. (c) H929 and U266 cells were treated with $12 \mathrm{nM}$ of bufalin in the absence and/or presence of $6 \mu \mathrm{M}$ of MK2206 for 24 and $48 \mathrm{~h}$, and the levels of the phosphorylated and total AKT, mTOR, P70 and 4EBP1 proteins were examined by western blot analysis. $\beta$-actin was used as a loading control. The values under the bands were representative of the mean quantitation ratios compared with the control groups. Experiments were performed in triplicate $\left({ }^{*} P<0.05 ;{ }^{* *} P<0.01\right)$

order to examine the cytocidal effect of bufalin and MK2206 in bortezomib-resistant myeloma cells (Supplementary Figure S4). Bufalin increased p-AKT levels in H929R and U266R cells (Figure 5a). Subsequently, H929R and U266R cells were treated with $24 \mathrm{nM}$ of bufalin alone and $12 \mu \mathrm{M}$ of MK2206 and/or in combination for $48 \mathrm{~h}$ and subjected to apoptosis analysis. The combination treatment induced apoptosis in H929R and U226R cells, respectively $(P<0.01$, Figure $5 \mathrm{~b})$. The induction of apoptosis was accompanied with a decrease in Bid protein levels, PARP cleavage, and activation of caspases $-3,-8$, and -9 in a time-dependent manner (Figure $5 \mathrm{c}$ and Supplementary Figure S2B). Furthermore, the downstream signaling proteins of the AKT/mTOR pathway were inhibited in H929R and U266R cells (Figure 5d). Taken together, the findings suggested that the combination treatment of bufalin with MK2206 attenuated bortezomib resistance in bortizomibresistant cells.
Bufalin and MK2206 inhibited MM cell growth in vivo. The efficacy of the combination treatment of the two regimens (bufalin and MK2206) was examined in a xenograft mouse model. Murine myeloma cells MOPC 315 were injected in the right flanks of the BALB/c nu/nu female mice and when the tumor volume was in the range of 200 to $400 \mathrm{~mm}^{3}$, the mice were randomized into four groups. The groups were treated with vehicle or bufalin and/or MK2206 for $10 \mathrm{~d}$ and the mice were sacrificed in order to extract the tumors. The combined treatment significantly blocked MM tumor growth compared with the single treatment (Figure 6a, $P<0.05$ ). The mice did not exhibit significant side effects, such as weight loss, following bufalin and/or MK2206 treatment (Figure 6b). The combined treatment decreased tumor cell proliferation, as assessed by Ki67 staining, and increased the percentage of apoptotic cells compared to the vehicle, bufalin and/or MK2206 treatment as demonstrated by the increase of TUNEL-positive cells (Figure 6c). 

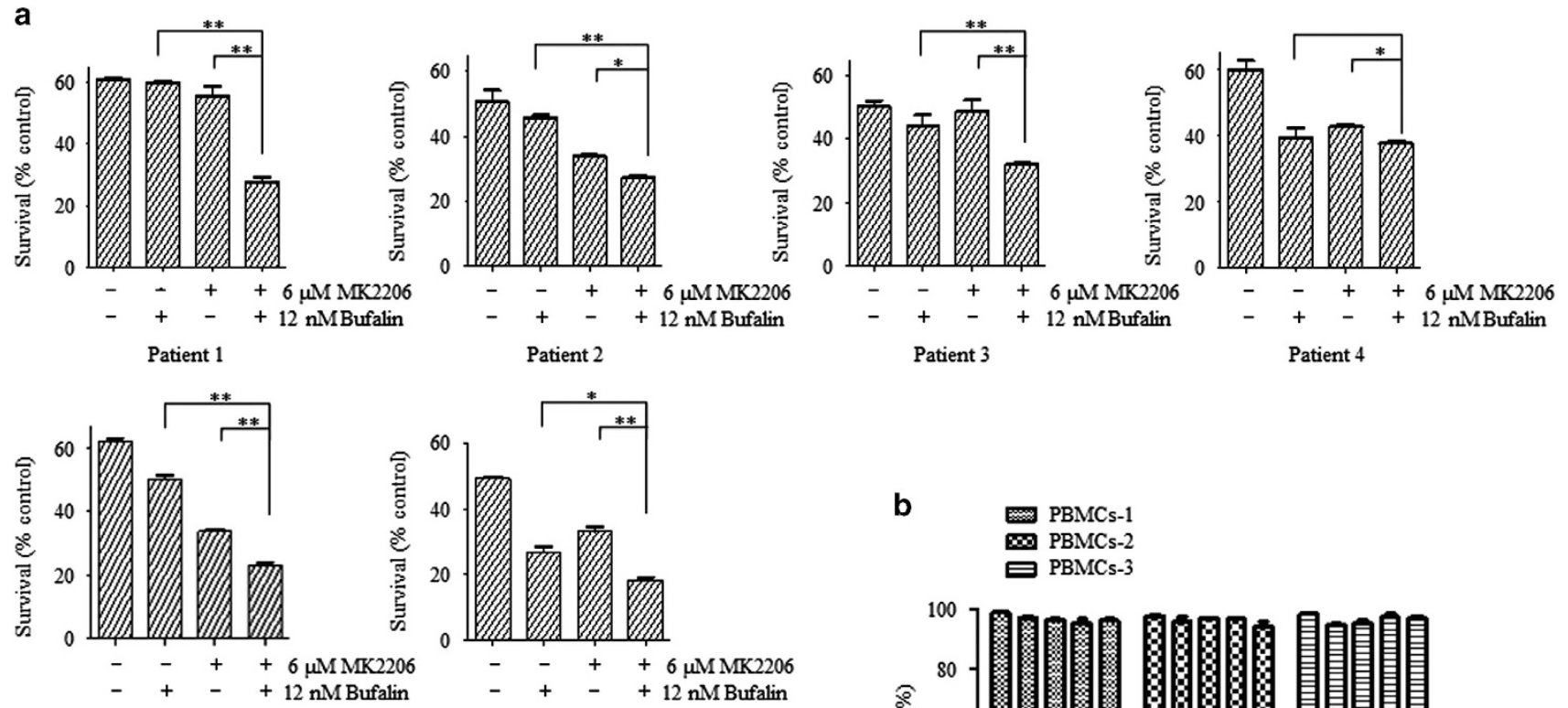

Patient 2

Patient 3

Patient 4

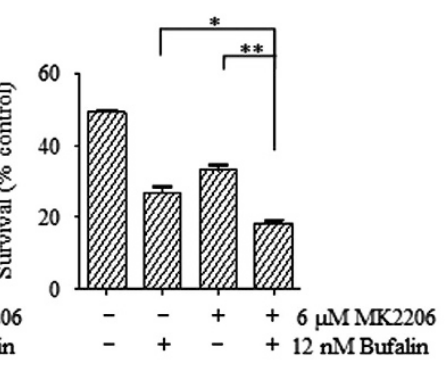

Patient 5

Patient 6

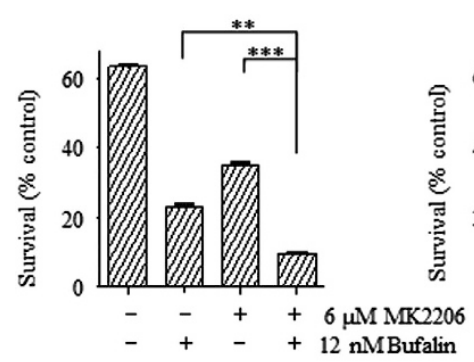

Patient 7
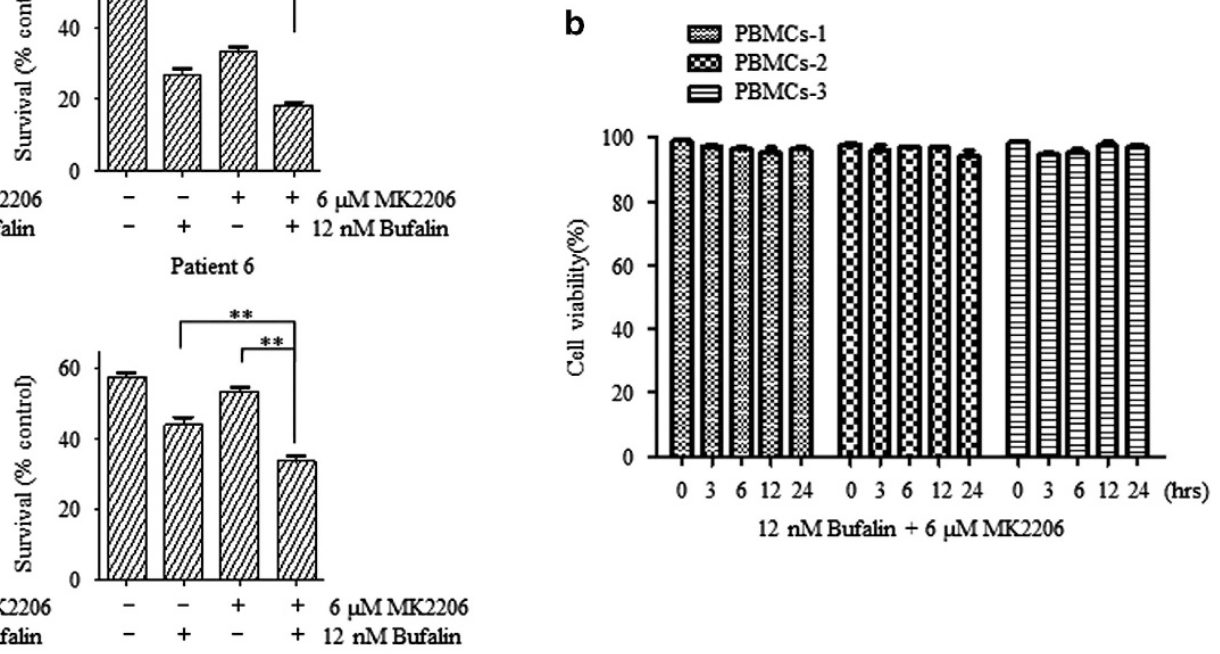

Figure 3 MK2206 enhanced the induction of apoptosis by bufalin in primary myeloma cells. (a) Patients' mononuclear cells were separated by Ficoll-Hipaque density sedimentation and CD138-positive cells were isolated and treated with $12 \mathrm{nM}$ of bufalin alone and/or in addition of $6 \mu \mathrm{M}$ of MK2206 for $48 \mathrm{~h}$. The survival rates were assessed by Annexin V/PI staining. (b) Freshly isolated PBMCs from 3 healthy donors were cultured with $12 \mathrm{nM}$ of bufalin and $6 \mu \mathrm{M}$ of MK2206 for $48 \mathrm{~h}$. The viability was assessed by the tryphan blue assay. Each bar represented the mean \pm S.E. of triplicate experiments $\left({ }^{*} P<0.05 ;{ }^{\star \star} P<0.01\right)$

The antitumor activity of the combination treatment was further assessed using a human MM (H929) xenograft model. In this model, $\mathrm{H} 929$ cells were injected subcutaneously in the right hind legs of NOD/SCID female mice and the treatment with vehicle, bufalin, MK2206 and/or combination was initiated when the tumor volume was in the range of 200 to $400 \mathrm{~mm}^{3}$. Following 12 days of treatment, NOD/SCID mice were killed and the tumor tissues were removed. Administration of bufalin and MK2206 resulted in a significant decrease in tumor volume compared with vehicle and/or single agent-treated animals (Figure $6 \mathrm{~d}, P<0.05$ ). This indicated that the combined treatment significantly inhibited MM tumor proliferation in vivo compared with the single treatment. Analysis of mouse weight revealed no significant differences between the treatment groups (Figure 6e). In addition, immunohistochemical analysis of Ki67 and TUNEL demonstrated inhibition of tumor cell proliferation and increased apoptosis in the tumors of the combined treatment group compared to the remaining three groups (Figure 6f).

\section{Discussion}

Multiple myeloma is an incurable plasma cell malignancy characterized by a high rate of disease recurrence and drug resistance, which has stimulated the development of novel therapeutics in order to improve the patient outcome. Bufalin is a bufadienolide extract from the traditional Chinese medicine Chan $\mathrm{Su}^{27}$ which has been widely used in China as an anodyne, cardiotonic, antimicrobial, local anesthetic and as a antineoplastic agent. Recent studies reveal that bufalin stimulates reactive oxygen species and inhibits the NF- $K B$, STAT3 and AKT signaling pathways. The modulation of these pathways contributes to the antitumor effects of bufalin. Nevertheless, recent findings reported by our group indicated that bufalin induced phosphorylation of AKT ( $p-A K T)$ in myeloma cells. The underlying mechanism of this discrepancy is currently unknown. However, the difference may be attributed to the different cell types and cellular content of the tissues. Considering the prosurvival effect of AKT, we hypothesized that the activation of AKT may neutralize the antitumor effects of bufalin. In order to test this hypothesis, evidence was provided that inhibition of AKT can enhance the anti-MM effects of bufalin. Initially, it was demonstrated that the combination of bufalin with the novel small-molecule allosteric inhibitor of AKT namely, MK2206, exerted greater inhibitory efficacy in H929, U266, RPMI8226 and LP-1 cells, compared 
a

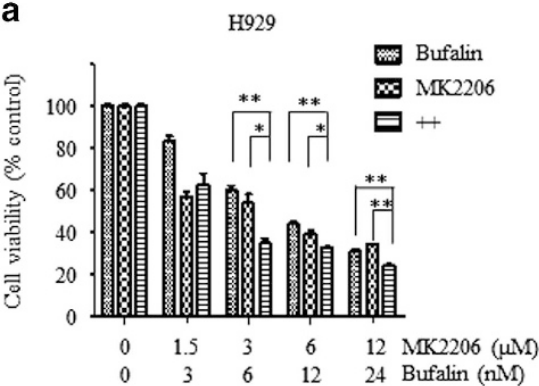

b

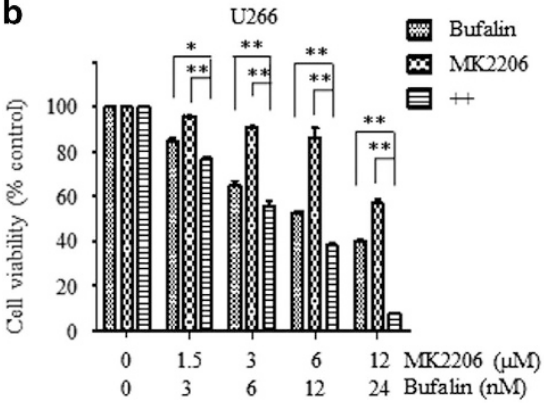

c

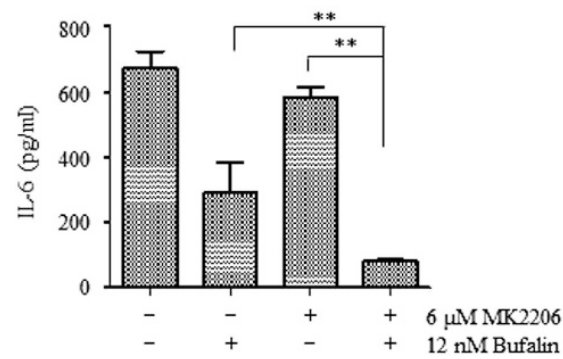

H929

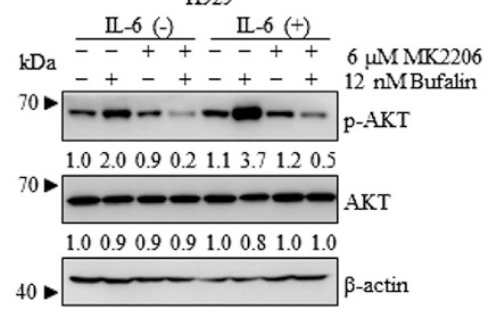

U266

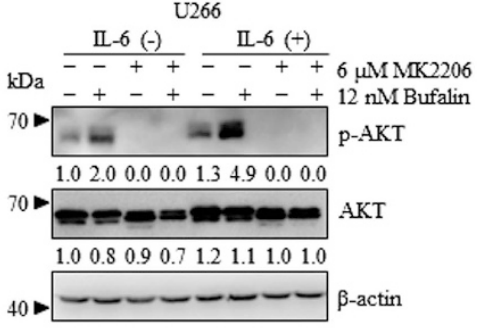

f

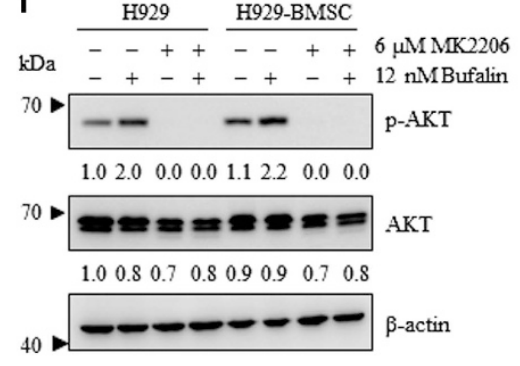

d
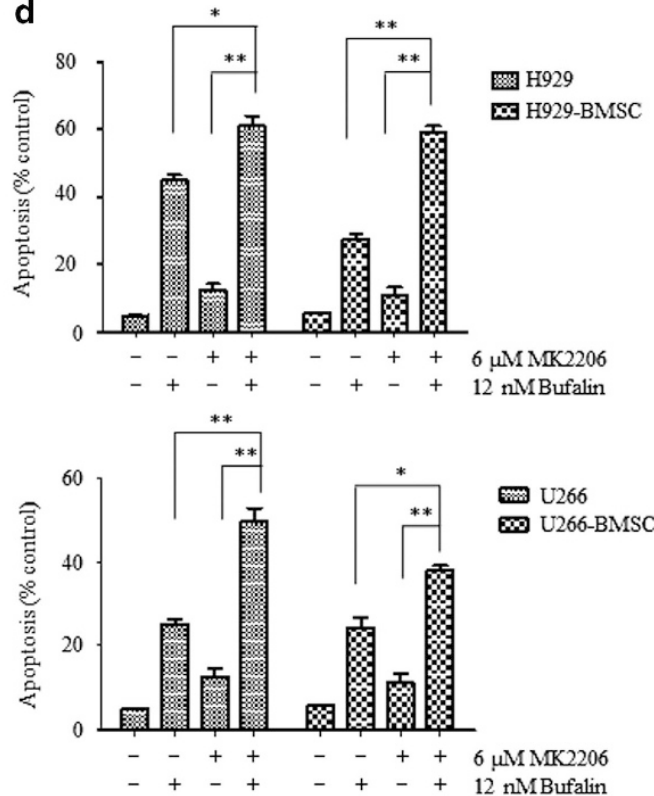

Figure 4 Bufalin and MK2206 surpassed IL-6-mediated cell growth and induced cooperative apoptosis of MM cells in the absence of BMSCs. (a and b) H929 and U266 cells were stimulated with IL-6 $(10 \mathrm{ng} / \mathrm{ml})$ for $1 \mathrm{~h}$ and subsequently cultured with the indicated reagents for $48 \mathrm{~h}$. Cell viability was measured by the CCK8 assay. Cell lysates were subjected to western blot analysis using anti-p-AKT, anti-AKT, and $\beta$-actin Abs. $\beta$-actin was used as a loading control. The values under the bands were representative of the mean quantitation ratios compared with the control groups. (c) U266 cells were treated with $12 \mathrm{nM}$ of bufalin in the absence and/or presence of $6 \mu \mathrm{M}$ of MK2206 for $48 \mathrm{~h}$ and subsequently centrifuged to obtain the supernatant. The samples were subjected to an IL-6 ELISA. (d and f) H929 and U266 cells were co-cultured with or without BMSCs for $48 \mathrm{~h}$ with $12 \mathrm{nM}$ of bufalin in the presence and/or absence of $6 \mu \mathrm{M}$ of MK2206, and the apoptotic rates were measured by flow cytometry. Subsequently, the cell lysates were subjected to western blot using anti-p-AKT, anti-AKT and anti- $\beta$-actin Abs. $\beta$-actin was used as a loading control. The values under the bands were representative of the mean quantitation ratios compared with the control groups. Each bar represented the mean \pm S.E. of triplicate experiments $\left({ }^{\star} P<0.05 ;{ }^{* *} P<0.01\right)$

with single administration of the compounds. Similarly to the effect caused by the AKT inhibitor, the knockdown of AKT in MM cells further enhanced the inhibition of cellular proliferation and the induction of cellular apoptosis by bufalin.

IL-6 is the most significant growth factor with regard to the extended survival and drug resistance of MM. A previous study indicated that IL-6, could upregulate Mcl-1 expression, while the corresponding $\mathrm{Mcl}-1$ gene was downregulated solely following IL-6 starvation. ${ }^{28}$ Thus, the combination effects of the two treatments in myeloma cells following IL-6 stimulation were examined, and it was demonstrated that concomitant treatment of bufalin with MK2206 could successfully abrogate IL-6-mediated cell growth and reduce IL-6 secretion in U266 cells.

$\mathrm{MM}$ pathogenesis and progression is associated with the bone marrow (BM) microenvironment and BMSCs are considered the major cell types that comprise the BM. In vitro studies have suggested that cell-cell contact between MM cells and BMSCs exerts a significant role in the support of the survival and growth of the plasma cells. ${ }^{29}$ In order to further investigate whether bufalin and MK2206 induced apoptosis of myeloma cells in the presence of BMSCs, MM cells were cocultured with BMSCs directly in the presence of bufalin and MK2206 alone and/or in combination. The results indicated that bufalin and MK2206 targeted MM cells directly and surpassed the cytoprotective effects mediated by the MMhost-BM microenvironment.

Adaptive resistance of myeloma to proteasome inhibitors represents a clinical challenge. Bortezomib is a first-class, reversible, boronate-type proteasome inhibitor widely used in $\mathrm{MM}^{30}$ In order to determine whether the combination of bufalin with MK2206 overcomes bortezomib resistance in MM cells, the previously characterized bortezomib-resistant MM cell lines (H929R and U266R) were used. Bufalin indicated 
a

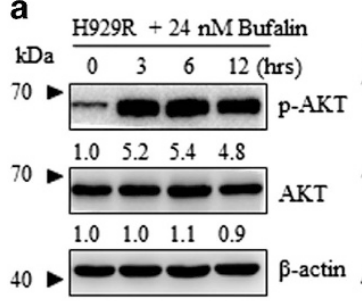

C

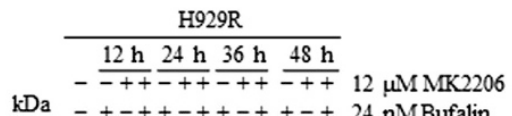

$\mathrm{kDa}-+-++-++-++-+24$ nMBufalin

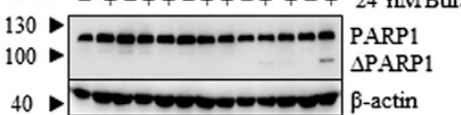

40 -actin

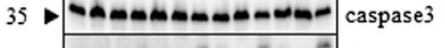

$15 \square \quad z$ caspase3

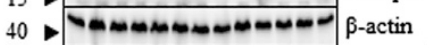

55 caspase9

40

40

U266R

$12 \mathrm{~h} 24 \mathrm{~h} 36 \mathrm{~h} 48 \mathrm{~h}$

$-\frac{12 \mathrm{~h}}{-++} \overline{-++} \frac{36 \mathrm{~h}}{-++} \frac{48 \mathrm{~h}}{-++} 12 \mu \mathrm{MMK} 2206$

$\mathrm{kDa}-+-++-++-++-+24 \mathrm{nMBufalin}$

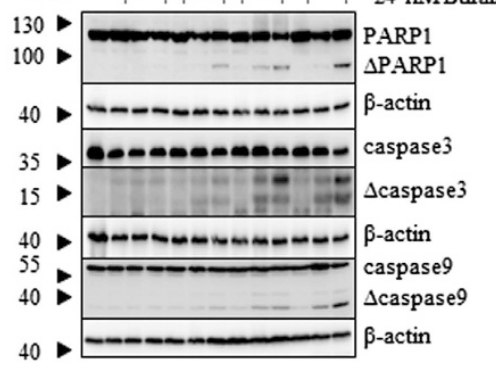

b

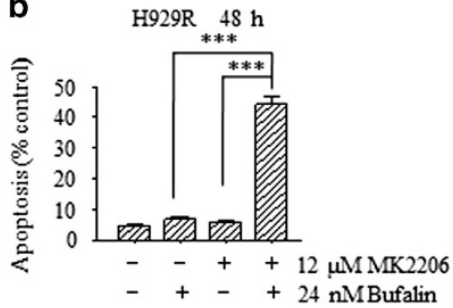

U266R $48 \mathrm{~h}$

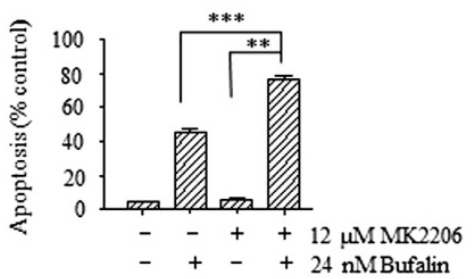

d

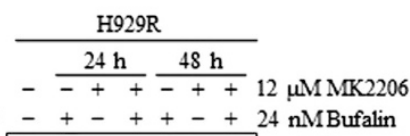

$\mathrm{kDa}-+-++-+24 \mathrm{nMBufalin}$
$70-\ldots-\mathrm{AKT}$

1.01 .80 .40 .32 .00 .00 .0

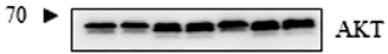

$1.01 .01 .21 .2 \quad 1.21 .21 .3$

40 -

250 -

1.01 .61 .21 .01 .71 .20 .9

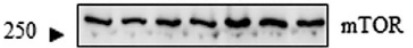

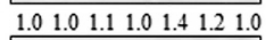

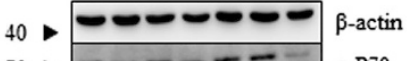

70 -

$\begin{array}{llllllll}1.0 & 0.9 & 1.2 & 0.6 & 1.1 & 1.2 & 0.2\end{array}$

$70 \triangleright$ -

1.01 .01 .01 .01 .11 .11 .0

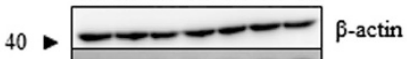

$15>-0---\infty$ p-4EBP1 $\begin{array}{lllllllll}1.0 & 0.8 & 1.0 & 0.5 & 0.7 & 0.5 & 0.4\end{array}$

15 -

1.01 .51 .21 .51 .01 .21 .8

$40 \rightarrow-1-$ Bactin

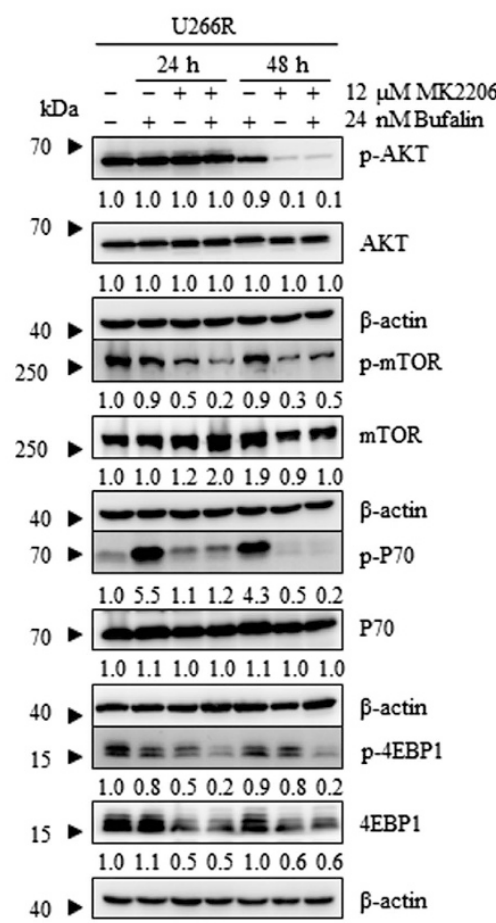

Figure 5 The combination of bufalin with Mk2206 surpassed bortezomib resistance in bortezomib-resistant cells. (a) H929R and U266R cells were treated with $24 \mathrm{nM}$ of bufalin for 3,6 and $12 \mathrm{~h}$ and subsequently subjected to Western blot analysis using anti-p-AKT, anti-AKT and anti- $\beta$-actin antibodies. $\beta$-actin was used as a loading control. The values under the bands were representative of the mean quantitation ratios compared with the control groups. (b) H929R and U266R cells were treated with $24 \mathrm{nM}$ of bufalin and/ or $12 \mu \mathrm{M}$ of MK2206 for $48 \mathrm{~h}$, and the apoptotic rates were analyzed by Annexin V/PI assay. The combination group exhibited statistically different values compared with the treatment of bufalin and/or MK2206 alone. Each bar represented the mean \pm SE (standard error) of 3 independent experiments. (c) H929R and U266R cells were treated with $24 \mathrm{nM}$ of bufalin in the absence and/or presence of $12 \mu \mathrm{M}$ of MK2206 for 12, 24, 36 and $48 \mathrm{~h}$ and protein lysates were subjected to immunoblot analysis using antibodies specific against PARP, caspase-3, caspase-9 and $\beta$-actin. $\beta$-actin was used as a loading control. (d) H929R and U266R cells were treated with $24 \mathrm{nM}$ of bufalin in the absence and/or presence of $6 \mu \mathrm{M}$ of MK2206 for 24 and $48 \mathrm{~h}$, and the levels of the phosphorylated and total AKT, mTOR, P70 and 4EBP1 proteins were examined by Western blot analysis. $\beta$-actin was used as a loading control. The values under the bands were representative of the mean quantitation ratios compared with the control groups $\left({ }^{*} P<0.05 ;{ }^{* *} P<0.01\right.$ )

significant anti-MM activity in H929R and U266R cells, while the addition of MK2206 confirmed the efficacy of the combination treatment to overcome bortezomib resistance.

The synergistic effect of the two treatments in primary MM cells was confirmed by analysis of the samples derived from eight newly diagnosed MM patients. In addition, the combination treatment did not exhibit toxic effects on peripheral mononuclear cells derived from three healthy volunteers. Furthermore, the synergism between bufalin and MK2206 was confirmed by the MM xenograft mouse model, using in humanderived and/or murine-derived MM cells. Taken collectively, the data suggest that bufalin and MK2206 may be promising candidates that can be further studied in clinical trials of MM patients.

Although the treatment strategies of MM have significantly improved, the development of drug resistance remains a serious disadvantage of the clinical efficacy of the drugs used for this disease. The clonal evolution of myeloma cells, the changes in the bone marrow microenvironment, the deregulation of microRNAs and the signaling interaction with the programmed death factor 1 (PD-1)/PDL1 contribute to the drug resistance noted in $\mathrm{MM}^{31}$ The induction of the AKT/ mTOR signaling by cytokines in the BM microenvironment mediates resistance to conventional and novel therapies. Neither bortezomib nor IMiDs could block the AKT/mTOR pathway. $^{32}$

Since MK2206 is an AKT inhibitor, and the effects of the combination treatment of MK2206 and bufalin were consistent with the knockout of AKT in the presence of bufalin. Previous studies reported that AKT and mTOR exhibit a complex interaction that is mediated by the modulation of PTEN and TSC1/2 protein expression. ${ }^{33}$ The mTOR kinase comprises 


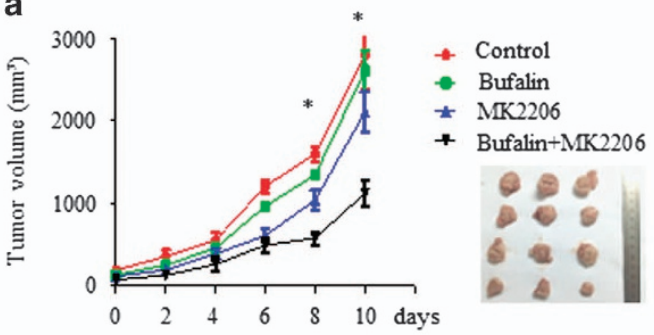

b

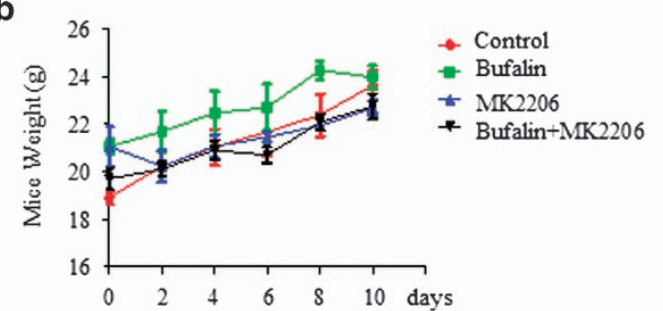

d

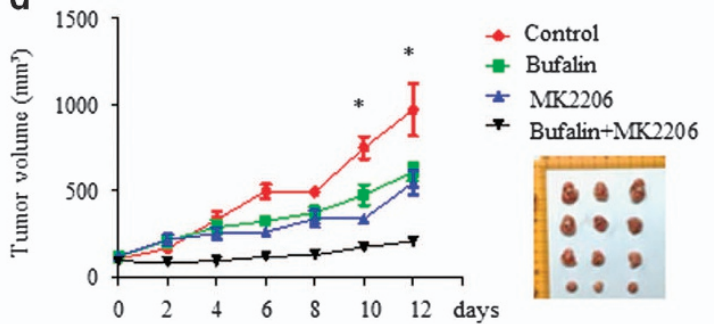

e
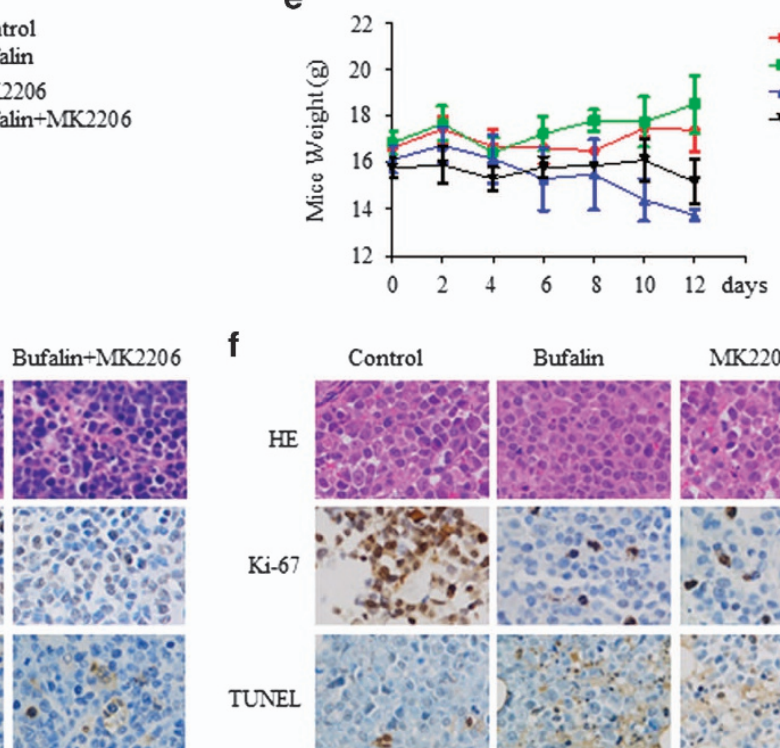

f

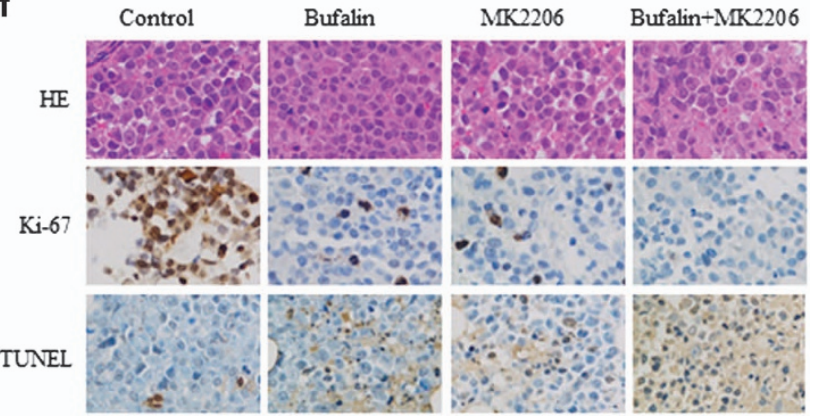

Figure 6 Bufalin and MK2206 inhibited MM cell growth in vivo. Mice bearing murine-derived MOPC315 MM tumors were treated with bufalin (1 mg/kg; intraperitoneally) daily in the presence and/or absence of MK2206 (120 mg/kg orally) for 10 days. Mice injected with human-derived H929 MM cells were treated with $1 \mathrm{mg} / \mathrm{kg}$ bufalin daily with or without $120 \mathrm{mg} / \mathrm{kg}$ MK2206 for 12 days. Tumor volume (a and $\mathbf{d}$ ) and the weight of mice ( $\mathbf{b}$ and $\mathbf{e}$ ) were measured every 2 days. The tumor volume was calculated using the following formula: $V=\left(\right.$ length $\times$ width $\left.^{2}\right) / 2$ (mean tumor volume \pm S.D., 3 mice per group). (c and $\mathbf{f}$ ) Tumor sections from four groups were subjected to immunostaining using TUNEL and anti-Ki67 Abs that demonstrated tumor cell apoptosis and proliferation. Experiments were performed in triplicate $\left({ }^{\star} P<0.05\right)$

two complexes namely, mTORC1 and mTORC2. The mTORC1 is regulated by P70S6K and 4EBP1 and the mTORC2 is regulated by AKT by phosphorylation of serine 473. The extended use of rapamycin and its derivatives that target mTORC1, inevitably leads to the development of tumordrug-resistance due to the elevated AKT activity. ${ }^{34}$ MK2206 was documented to inhibit all members of the AKT/mTOR pathway by previous reports. In the current study a decrease in the phosphorylation of AKT, mTOR, P70 and 4EBP1 proteins was observed following the combination treatment that contributed to avoiding drug resistance, with regard to the AKT/mTOR signaling pathway.

\section{Materials and Methods}

Cell culture. The human MM cell lines NCl-H929 (referred to as H929), U266, LP-1, RPMI8226 and the murine MM cell line MOPC315 were purchased from the American Type Culture Collection (ATCC). H929R and U266R cells were established by constant stimulation using bortezomib at a gradually increasing concentration range. The cells were split twice every week and the bortezomib dose was gradually increased with administration of $4 \mathrm{nM}$ of the compound per month to a final dose of $50 \mathrm{nM}$ following 12 months of treatment. The cells were maintained in $50 \mathrm{nM}$ of bortezomib for 3 months and subsequently in bortezomib-free medium for 2 weeks prior to the experimental treatment. All cell lines were cultured in RPMI-1640 medium (Sigma-Aldrich, St. Louis, MO, USA), supplemented with 10\% (v/v) heat-inactivated fetal bovine serum (HyClone, Logan, UT, USA), $100 \mathrm{U} / \mathrm{ml}$ penicillin and $100 \mu \mathrm{g} / \mathrm{ml}$ streptomycin (Invitrogen, Paisley, Scotland, UK), in a humidified incubator at $37{ }^{\circ} \mathrm{C}$ in the presence of $5 \% \mathrm{CO}_{2} / 95 \%$ air.

Reagents. Bufalin (3beta, 5beta-3, 14-Dihydroxy-bufa-20, 22-dienolide) was purchased from Tauto Biotech Co., Ltd., Shanghai, China, with $>98 \%$ purity as determined by HPLC analysis. MK2206 and Captisol were from Selleck Chemicals. The aforementioned drugs were prepared in Dimethyl sulfoxide (DMSO), aliquoted and stored at $-20^{\circ} \mathrm{C}$.

Primary MM cells and normal mononuclear cells. Written informed consent was obtained from eight myeloma patients and three healthy volunteers prior to sample collection, for the use of their specimens in the study protocol. The study was conducted in accordance with the Declaration of Helsinki that ensures the safety and well-being of the subjects and the integrity of the data. The protocol was approved by the Clinical Investigational Reviewing Board of the Shanghai Second Medical University, China. Mononuclear cells (MNCs) were isolated from BM specimens of MM patients by Ficoll-Hipaque (Pharmacia, Piscataway, NJ, USA) density sedimentation. $\mathrm{CD}_{138^{+}}$cells were selected from MNCs using EasyStep $\mathrm{CD}_{138^{+}}$magnetic nanoparticles, as described in the instructions from the manufacturer's protocol (Stem Cell Technologies, Vancouver, BC, Canada). Peripheral blood mononuclear cells (PBMCs) were obtained from healthy volunteers in the same way.

Cell viability assay. MM cells $\left(0.2-1 \times 10^{5}\right.$ per $\left.200 \mu l\right)$ were seeded in 96 -well plates and incubated with various drug concentrations in triplicate for the indicated 
time periods. The cells were incubated with $10 \mu \mathrm{l}$ of Cell Counting kit-8 (Dojindo, Kumamoto, Japan), according to the instruction provided in the protocol of the manufacturer. The experiments were conducted three times.

Cell cycle assay. Cells were treated with bufalin $(0,3,6$ and $12 \mathrm{nM})$ for $48 \mathrm{~h}$ and then collected and washed twice with phosphate-buffered saline (PBS). After fixed with $75 \%$ cold ethanol at $-20^{\circ} \mathrm{C}$ overnight, cells were incubated with RNase $(100 \mathrm{mg} / \mathrm{ml})$ for $30 \mathrm{~min}$ at $37^{\circ} \mathrm{C}$. Cells were stained with propidium iodide (Sigma-Aldrich, St Louis, MO, USA; $250 \mathrm{mg} / \mathrm{ml}$ ) and incubated for another $15 \mathrm{~min}$ in the dark. Then, cells were analyzed by flow cytometry.

Cell apoptosis assays. Quantification of apoptosis was determined by the Annexin-V apoptosis detection kit (BD Pharmingen) following the instructions of the manufacturer protocol. Annexin-V-positive and propidium iodide-negative cells were considered to be in the early apoptotic phase, whereas the cells that exerted positive staining for Annexin-V and propidium iodide were considered to be in the late apoptotic and/or necrotic stage. All data were collected, stored, and analyzed by LYSIS II software (BD Biosciences, San Diego, CA, USA). For primary myeloma samples, cells were selected from MNCs using EasyStep CD138+ magnetic nanoparticles and stained with Annexin-V-FITC, and propidium iodide at room temperature for $30 \mathrm{~min}$. The cells were washed with $1 \times$ binding buffer twice, and analyzed using a LSR II flow cytometer (BD biosciences).

Western blot. MM cells were harvested, washed with PBS twice and lysed with lysis buffer (62.5 mM Tris-HCL, pH=6.8, $100 \mathrm{mM}$ DTT, 2\% SDS, 10\% glycerol). The samples were centrifuged at $12000 \times g$ for $10 \mathrm{~min}$. The protein concentration of the cell lysates was measured using the Bradford assay. The protein samples (10-40 $\mu \mathrm{g}$ ) were equally loaded on 6-15\% SDS-polyacrylamide gels, electrophoresed and transferred to nitrocellulose membranes (Amersham Bioscience, Buckinghamshire, UK). Following $2 \mathrm{~h}$ of blocking with $5 \%$ of nonfat milk in PBS at room temperature, the membranes were incubated with different antibodies namely, anti-phospho (p)-AKT (Ser473), anti-AKT, anti-p-mTOR (Ser248), antimTOR, anti-ribosomal P70S6 kinase (P70S6k), anti-p-P70S6K (Thr389), antieukaryotic binding proteins (4EBP1), anti-p-4EBP1 (Thr70), anti-caspase-3, anti-cleaved caspase-3, anti-caspase-8, anti-Bid (Cell Signaling Technology, Beverly, MA, USA), anti-PARP1, anti-caspase-9 and anti-cleaved caspase-9 (Santa Cruz Biotechnology, CA, USA), overnight at $4{ }^{\circ} \mathrm{C}$. The following morning the membranes were incubated with HRP-linked secondary antibodies for $2 \mathrm{~h}$ at room temperature. The protein bands were detected by chemiluminescence phototope-HRP kit (Merck Millipore, Jaffrey, NH, USA) according to the instructions provided by the manufacturer. HRP-linked anti- $\beta$-actin antibody was used as a loading control.

Cytokine ELISA. U266 cells were plated at a density of $5 \times 10^{5}$ cells per well and cell culture supernatants were collected following $48 \mathrm{~h}$. The concentration of IL-6 was determined by ELISA assay kits (R\&D Systems, Minneapolis, MN, USA), whereas the absorbance was measured using an ELISA plate reader at specific wavelengths determined by the assay kit.

RNA interference. A retrovirus with target sites in the AKT gene that were previously reported ${ }^{19,35}$ were packaged with plasmids containing a non-target control shRNA (NC) in HEK293T cells by co-transfection with pSIREN-RetroQ, pEQPAM (containing gag-pol, produced by Dr. Lishan Su at UNC, Chapel Hill, NC, USA) and VSVG (Clontech Laboratories, Mountain View, CA, USA, T-334350). Following transfection for $48 \mathrm{~h}$, the viral supernatant was collected, filter-sterilized and added to $\mathrm{H} 929$ cells $\left(2 \times 10^{5}\right.$ cells/well) in 6-well plates in the presence of a medium containing $8 \mu \mathrm{g} / \mathrm{ml}$ of polybrene (Millipore, TR-1003-G). Puromycin $(2.0 \mu \mathrm{g} /$ $\mathrm{ml}$, Calbiochem, 540411) was used to select the stable-transfected cells at a $96 \mathrm{~h}$ time period.

Co-culture. Bone marrow stromal cells (BMSCs) were isolated from bone marrow aspirates of MM patients as previously described. ${ }^{26}$ For direct co-culture, $5 \times 10^{5}$ BMSCs cells were seeded in a $10 \mathrm{~cm}$ Petri dish and $5 \times 10^{5} \mathrm{MM}$ cells were added $24 \mathrm{~h}$ following BMSCs seeding. Following $48 \mathrm{~h}$ of incubation, the MM cell lines were collected.

Xenograft mouse model. BALB-c nu/nu female mice aged 4-6 weeks and NOD-SCID female mice aged 4-6 weeks were used in the experiments. MOPC315 cells were injected subcutaneously in the right flanks of the BALB-c nu/nu female mice $\left(0.2 \mathrm{ml}\right.$ per mouse containing $2 \times 10^{7}$ cells $)$ and the H929 cells $(0.2 \mathrm{ml}$ cell suspension containing 50\% Matrigel (Corning, Bedford, MA, USA) per mouse and $1 \times 10^{7}$ cells) were injected subcutaneously in the right hind leg of sublethally irradiated (200 cGy) female non-obese diabetes/severe combined immunodeficiency (NOD/SCID) mice. Tumor growth and mouse weight were monitored every 2 days. The mice were randomized into four groups (3 mice per group: vehicle control, bufalin, MK2206, bufalin+MK2206) when the tumor volume reached a range of 200 to $400 \mathrm{~mm}^{3}$. Bufalin was administered to the mice intraperitoneally at a daily dose of $1 \mathrm{mg} / \mathrm{kg}$. MK2206 was administered to the mice orally, at a dose of $120 \mathrm{mg} /$ $\mathrm{kg}$, three times per week. Following successful treatment for 10 days, the groups of BALB-c nu/nu female mice were killed and the tumor tissues were removed. Following treatment for 12 days, the groups of NOD-SCID female mice were killed and the tumor tissues were removed. The difference in the time span of administration was due to the different cell types. The study was approved by the Shanghai Jiao Tong University School of Medicine Institutional Animal Care \& Use Committee. $^{36}$

Statistical analysis. All experiments were carried out in triplicate. Statistical significance of differences observed in drug-treated versus control cultures was determined using the Wilcoxon signed ranks test. In all cases, a $P$-value of $<0.05$ $(P<0.05)$ was considered statistically significant. The interaction between Bufalin and MK2206 was analyzed by isobologram analysis using the CompuSyn software program (ComboSyn, Inc., Paramus, NJ, USA) in order to determine whether the combination was antagonistic or synergistic. The combination index (Cl) lower that was $<1.0$ indicated a synergistic effect, as previously described.

\section{Conflict of Interest}

The authors declare no conflict of interest.

Acknowledgements. This work has been supported by grants from National Basic Research Program of China (973 Program) (NO. 2015CB910403); National Natural Science Foundation of China (81570118 and 8167010683). Science and Technology Committee of Shanghai (15401901800 and 16ZR1421400).

\section{Author contributions}

RFX and YW participated in the study design and carried out the majority of the experimental work. NZ and YC aided with the examination of MMP and apoptosis by flow cytometry. YW and WBX participated in the collection of the clinical information and data from the patients. JT conducted the statistical analysis. HY, YLW and JML participated in the study design, the coordination of different study groups and the revision of the manuscript.

1. Siegel RL, Miller KD, Jemal A. Cancer statistics. CA Cancer J Clin 2016; 66: 7-30.

2. Rossi M, Di Martino MT, Morelli E, Leotta M, Rizzo A, Grimaldi A et al. Molecular targets for the treatment of multiple myeloma. Curr Cancer Drug Targets 2012; 12: 757-767.

3. Fresno Vara JA, Casado E, de Castro J, Cejas P, Belda-Iniesta C, González-Barón M. PI3K Akt signalling pathway and cancer. Cancer Treat Rev 2004; 30: 193-204.

4. Hsu J, Shi Y, Krajewski S, Renner S, Fisher M, Reed JC et al. The AKT kinase is activated in multiple myeloma tumor cells. Blood 2001; 98: 2853-2855.

5. Cao H, Zhu K, Qiu L, Li S, Niu H, Hao M et al. Critical role of AKT protein in myeloma-induced osteoclast formation and osteolysis. J Biol Chem 2013; 288: 30399-30410.

6. Morgan GJ, Walker BA, Davies FE. The genetic architecture of multiple myeloma. Nat Rev Cancer 2012; 12: 335-348.

7. DeFeo-Jones D, Barnett SF, Fu S, Hancock PJ, Haskell KM, Leander KR et al. Tumor cell sensitization to apoptotic stimuli by selective inhibition of specific Akt/PKB family members. Mol Cancer Ther 2005; 4: 271-279.

8. Barnett SF, Defeo-Jones D, Fu S, Hancock PJ, Haskell KM, Jones RE et al. Identification and characterization of pleckstrin-homology-domain-dependent and isoenzyme-specific Akt inhibitors. Biochem J 2005; 385: 399-408.

9. Hirai H, Sootome H, Nakatsuru Y, Miyama K, Taguchi S, Tsujioka K et al. MK-2206, an allosteric Akt inhibitor, enhances antitumor efficacy by standard chemotherapeutic agents or molecular targeted drugs in vitro and in vivo. Mol Cancer Ther 2010; 9: 1956-1967.

10. Yap TA, Yan L, Patnaik A, Fearen I, Olmos D, Papadopoulos K et al. First-in-man clinical trial of the oral pan-AKT inhibitor MK-2206 in patients with advanced solid tumors. J Clin Oncol 2011; 29: 4688-4695.

11. Hong Z, Chan K, Yeung HW. Simultaneous determination of bufadienolides in the traditional Chinese medicine preparation, liu-shen-wan, by liquid chromatography. J Pharm Pharmacol 1992; 44: 1023-1026.

12. Morishita S, Saito T, Mishima Y, Mizutani A, Hirai Y, Kawakami M. Pharmacological studies of Senso (Ch'an Su) containing drugs. Nihon Yakurigaku Zasshi 1986; 87: 361-378. 
13. Zhang LS, Nakaya K, Yoshida T, Kuroiwa Y. Bufalin as a potent inducer of differentiation of human myeloid leukemia cells. Biochem Biophys Res Commun 1991; 178: 686-693.

14. Zhang L, Nakaya K, Yoshida T, Kuroiwa Y. Induction by bufalin of differentiation of human leukemia cells HL60, U937, and ML1 toward macrophage/monocyte-like cells and its potent synergistic effect on the differentiation of human leukemia cells in combination with other inducers. Cancer Res 1992; 52: 4634-4641.

15. Hashimoto S, Jing Y, Kawazoe N, Masuda Y, Nakajo S, Yoshida T et al. Bufalin reduces the level of topoisomerase $\|$ in human leukemia cells and affects the cytotoxicity of anticancer drugs. Leuk Res 1997; 21: 875-883.

16. Chen A, Yu J, Zhang L, Sun Y, Zhang Y, Guo H et al. Microarray and biochemical analysis of bufalin-induced apoptosis of HL-60 Cells. Biotechnol Lett 2009; 31: 487-494.

17. Tian $X$, Yin H, Zhang S, Luo $Y, X u K, M a ~ P$ et al. Bufalin loaded biotinylated chitosan nanoparticles: an efficient drug delivery system for targeted chemotherapy against breast carcinoma. Eur J Pharm Biopharm 2014; 87: 445-453.

18. Meng Z, Yang P, Shen Y, Bei W, Zhang Y, Ge Y et al. Pilot study of huachansu in patients with hepatocellular carcinoma, nonsmall-cell lung cancer, or pancreatic cancer. Cancer 2009; 115: 5309-5318.

19. Huang H, Cao Y, Wei W, Liu W, Lu SY, Chen YB et al. Targeting poly (ADP-ribose) polymerase partially contributes to bufalin-induced cell death in multiple myeloma cells. PLOS ONE 2013; 8: e66130.

20. Yu W, Chen Y, Xiang R, Xu W, Wang Y, Tong J et al. Novel phosphatidylinositol 3-kinase inhibitor BKM120 enhances the sensitivity of multiple myeloma to bortezomib and overcomes resistance. Leuk Lymphoma 2016; 58: 428-437.

21. Keane NA, Glavey SV, Krawczyk J, O'Dwyer M. AKT as a therapeutic target in multiple myeloma. Expert Opin Ther Targets 2014; 18: 897-915.

22. Brotin E, Meryet-Figuiere M, Simonin K, Duval RE, Villedieu M, Leroy-Dudal J et al. Bcl-XL and MCL-1 constitute pertinent targets in ovarian carcinoma and their concomitant inhibition is sufficient to induce apoptosis. Int J Cancer 2010; 126: 885-895.

23. Klein B, Zhang XG, Lu ZY, Bataille R. Interleukin-6 in human multiple myeloma. Blood 1995 85: 863-872.

24. Hilbert DM, Kopf M, Mock BA, Kohler G, Rudikoff S. Interleukin 6 is essential for in vivo development of B lineage neoplasms. J Exp Med 1995; 182: 243-248.

25. Schwab G, Siegall CB, Aarden LA, Neckers LM, Nordan RP. Characterization of an interleukin-6-mediated autocrine growth loop in the human multiple myeloma cell line. Blood 1991; 77: 587-593.

26. Can A, Balci D. Isolation, culture, and characterization of human umbilical cord stromaderived mesenchymal stem cells. Methods Mol Biol 2011; 698: 51-62.

27. Steyn PS, van Heerden FR. Bufadienolides of plant and animal origin. Nat Prod Rep 1998; 15: $397-413$.
28. Jourdan M, Veyrune JL, De Vos J, Redal N, Couderc G, Klein B. A major role for Mcl-1 antiapoptotic protein in the IL-6-induced survival of human myeloma cells. Oncogene 2003; 22: 2950-2959.

29. Wallace SR, Oken MM, Lunetta KL, Panoskaltsis-Mortari A, Masellis AM. Abnormalities of bone marrow mesenchymal cells in multiple myeloma patients. Cancer 2001; 91: 1219-1230.

30. Moreau P, Richardson PG, Cavo M, Orlowski RZ, San Miguel JF, Palumbo A et al. Proteasome inhibitors in multiple myeloma: 10 years later. Blood 2012; 120: 947-959.

31. Yang WC, Lin SF. Mechanisms of drug resistance in relapse and refractory multiple myeloma. Biomed Res Int 2015; 2015: 341430.

32. Hideshima T, Anderson KC. Molecular mechanisms of novel therapeutic approaches for multiple myeloma. Nat Rev Cancer 2002; 2: 927-937.

33. Hay N. The Akt-mTOR tango and its relevance to cancer. Cancer Cell 2005; 8: $179-183$.

34. Gupta M, Ansell SM, Novak AJ, Kumar S, Kaufmann SH, Witzig TE. Inhibition of histone deacetylase overcomes rapamycin-mediated resistance in diffuse large B-cell lymphoma by inhibiting Akt signaling through mTORC2. Blood 2009; 114: 2926-2935.

35. Chahdi A, Sorokin A. Endothelin-1 couples betaPix to p66Shc: role of betaPix in cell proliferation through $\mathrm{FOXO3a}$ phosphorylation and p27kip1 down-regulation independently of Akt. Mol Biol Cell 2008; 19: 2609-2619.

36. Roussel M, Moreau P, Huynh A, Mary JY, Danho C, Caillot D et al. Bortezomib and high-dose melphalan as conditioning regimen before autologous stem cell transplantation in patients with de novo multiple myeloma: a phase 2 study of the Intergroupe Francophone du Myelome (IFM). Blood 2010; 115: 32-37.

Cell Death and Disease is an open-access journal published by Nature Publishing Group. This work is

licensed under a Creative Commons Attribution 4.0 International License. The images or other third party material in this article are included in the article's Creative Commons license, unless indicated otherwise in the credit line; if the material is not included under the Creative Commons license, users will need to obtain permission from the license holder to reproduce the material. To view a copy of this license, visit http://creativecommons.org/licenses/by/4.0/

(C) The Author(s) 2017

Supplementary Information accompanies this paper on Cell Death and Disease website (http://www.nature.com/cddis) 